\title{
Eficacia de la intervención en las dimensiones del lenguaje en alumnado con Síndrome de Down. Una revisión teórica
}

\author{
Diana Marín Suelves. Universitat de Valencia \\ Miriam Cuenca Valero. Universitat de Valencia
}

Recepción: 6.08.2018| Aceptado: 2.10.2018

Correspondencia a través de ORCID: Diana Marín Suelves

iD $0000-0002-5346-8665$

Citar: Marín Suelves, D. y Cuenca Valero, M. (2018). Eficacia de la intervención en las dimensiones del lenguaje en alumnado con Síndrome de Down. Una revisión teórica. ReiDoCrea, 7, 330-347.

\begin{abstract}
Resumen: El Síndrome de Down es el resultado de una anomalía cromosómica por la que los núcleos de las células del organismo humano poseen 47 cromosomas en lugar de 46, perteneciendo el cromosoma extra al par 21. Dicho síndrome es la causa de afecciones en el habla y el lenguaje las cuales pueden ser observadas, especialmente, durante la etapa escolar. Existen diferentes intervenciones en las áreas del lenguaje para abordar las dificultades que comúnmente presentan estos alumnos. En estas líneas, se presenta una revisión teórica para analizar, por una parte, el enfoque y objetivos de las intervenciones y, por otra, la eficacia de las realizadas en los últimos años. Los resultados muestran que las intervenciones dirigidas a las personas con SD se centran en las dificultades las áreas del lenguaje, especialmente en la morfosintaxis y en la pragmática. A partir del análisis y comparación de los veinte estudios analizados es posible establecer pautas para el diseño de intervenciones, y en un futuro, poder implementar programas de intervención que se ajusten a las necesidades de esta población, con ciertas garantías de éxito.
\end{abstract}

Palabras clave: Discapacidad intelectual | Eficacia del tratamiento

Efficacy of the intervention in the dimensions of language in students with Down Syndrome. A theoretical review

\begin{abstract}
Down syndrome is the result of a chromosomal abnormality whereby the nuclei of the cells of the human organism possess 47 chromosomes instead of 46 , the extra chromosome belonging to the 21 pair. This syndrome is the cause of affections in speech and language which can be observed, especially during the school stage. There are different interventions in the language areas to address the difficulties that these students commonly present. In these lines, a theoretical review is presented to analyze, on the one hand, the focus and objectives of the interventions and, on the other, the effectiveness of those carried out in recent years. The results show that interventions aimed at people with DS focus on language areas, especially in morphosyntax and pragmatics. From the analysis and comparison of the twenty studies analyzed it is possible to establish guidelines for the design of interventions, and in the future, to be able to implement intervention programs that adjust to the needs of this population, with certain guarantees of success.
\end{abstract}

Keywords: Intelectual Disability | Treatment Effectiveness

\section{Introducción}

Según Pérez (2014), el origen del síndrome de Down se remonta hacia el siglo VII d. C. mencionándose a personas con características similares, además, también se contaba con estatuillas que se asemejaban. Ya es en el siglo XVI cuando se representaban diferentes pictografías dónde se podían apreciar imágenes de personas con los rasgos característicos del síndrome. Hacia 1866 el síndrome de Down fue descrito por primera vez con sus características por John Langdon Down en un grupo de pacientes con alteraciones intelectuales, creyéndose casi durante un siglo, que el síndrome que describió Down era un estado regresivo. Flores (2013) argumenta que durante esta época se consideraba a estos niños como mongólicos, creyendo que las diferentes razas humanas estaban relacionadas con los distintos estadios evolutivos de la especie humana. Fue en el s. XX cuando surgió la primera descripción científica 
médica que explicara la existencia del síndrome. Tal y como afirma Pérez (2014), en 1932 Waardenburg sugiere la probabilidad de un reparto anormal de los cromosomas, lo que se demostró en 1956 cuando Jerome Lejuene descubrió la existencia de material genético extra en el cromosoma 21. Tras esto, fue en 1961 cuando el nombre de su descubridor, John Langdon Down, fue adoptado para referirse de manera oficial a este síndrome.

Actualmente, de acuerdo con Flórez y Ruiz (2006, p. 48), el síndrome de Down se puede definir como:

Una entidad que en la actualidad constituye la causa genética más frecuente de discapacidad intelectual y malformaciones congénitas. Es el resultado de una anomalía cromosómica por la que los núcleos de las células del organismo humano poseen 47 cromosomas en lugar de 46, perteneciendo el cromosoma excedente o extra al par 21 [...] El sistema más comúnmente afectado es el sistema nervioso y dentro de él, el cerebro y el cerebelo; por este motivo, casi de manera constante la persona con síndrome de Down presenta, en grado variable, discapacidad intelectual.

Según Gallardo (2000), el síndrome de Down (SD) es la forma sindrómica más frecuente de discapacidad intelectual en la población y, por ende, de los más habituales en el ámbito escolar, dado que en la actualidad prima el principio de inclusión educativa.

Por lo que respecta al tratamiento, no existe un único tratamiento para el síndrome de Down. Se realiza un seguimiento de pautas para lograr mejoría y aumentar la autonomía del alumnado. En este sentido, Pérez (2014) recomienda realizar pruebas oftalmológicas, revisiones gastrointestinales y una dieta rica en fibra, realizar cardiogramas durante los dos primeros meses de vida, planificar revisiones odontológicas y apoyar con fonoaudiología, fisioterapia y pedagogía especial para el perfeccionamiento del lenguaje y cuidado personal, brindando un ambiente enriquecedor y estimulante.

Según indican Galeote, Rey, Checa y Sebastián (2010), El desarrollo del lenguaje en las personas con SD conforma una de las áreas más afectadas y, por tanto, donde los niños con síndrome de Down manifiestan mayores dificultades. De acuerdo con estos autores, el desarrollo evolutivo de los sujetos que manifiestan síndrome de Down es muy diferente a las personas con desarrollo típico, lo cual provoca que el nivel lingüístico del sujeto no sea el adecuado a su edad cronológica.

Respecto a la comunicación preverbal y prelenguaje durante la primera infancia, la interacción y la comunicación de los bebés es de gran relevancia para que el proceso de adquisición del lenguaje se ejecute con normalidad. El desarrollo lingüístico de los niños con SD durante la etapa prelingüística se ve condicionado por la discapacidad intelectual que presentan lo que supone, de acuerdo con Domènech (2008), que haya limitaciones sustanciales en el funcionamiento de la persona en relación con la inteligencia conceptual, emocional y social, y en relación con las habilidades adaptativas. La adquisición del lenguaje y de la comunicación sigue el mismo orden de etapas, pero hay que tener en cuenta que el ritmo puede variar puesto que cada niño es diferente. Así pues, Domènech (2008) afirma que durante la etapa prelingüística, la cual va de los 0 a los 12 meses, es cuando el bebé capta los sonidos del habla de la madre y aprende a discriminar y a producir los fonemas, aparece el balbuceo y el gesto significativo. En cuanto a los niños con SD, llevan a cabo un proceso más lento con etapas más largas, tanto que la etapa prelingüística se puede alargar hasta los 24 meses, y la aparición de las primeras palabras de los 2 a los 6 años. De acuerdo con este mismo autor, los bebés con SD se integran más tarde en el sistema comunicativo 
debido a que su reactividad e iniciativa de diálogo es más lenta y tardía. Además, a veces, son poco reactivos a las demandas del adulto y el contacto ocular es más retrasado. Todo este retraso supone que durante un tiempo hay una falta de captación de la conversación y del diálogo interactivo. Por tanto, desde un principio, el entorno del niño debe favorecer la interacción para que surjan de manera natural las primeras intenciones comunicativas y su competencia lingüística se vaya forjando poco a poco.

En cuanto al desarrollo del lenguaje no solo existen diferencias entre el lenguaje con respecto otras áreas, sino que dentro del área del lenguaje las personas con SD presentan habilidades diferentes en los distintos componentes del lenguaje o entre los procesos léxicos. Por ejemplo, Galeote et al. (2010) opinan que su nivel léxico es superior al morfosintáctico y la comprensión la tienen más desarrollada que la producción ya que son capaces de entender el léxico o ciertas órdenes, pero les resulta difícil reproducirlo dentro de un contexto. Kumin (1997) señala que estas dificultades para expresarse pueden ser debidas a sus problemas cognitivos y motores, por ejemplo, presentan dificultad a la hora de secuenciar las palabras para expresar una idea o pedir una aclaración cuando no entienden algo que se le ha dicho. A pesar de las diferencias existentes en las diferentes áreas del lenguaje, el desarrollo del mismo persiste durante la adolescencia ya que tal y como indica Fowler (1990) "El desarrollo del lenguaje, en tanto en lo que se refiere a la comprensión como a la producción, continúa a lo largo de la adolescencia y la primera etapa del periodo adulto, con distintos niveles en cuanto a comprensión y producción" (citado en Moraleda, 2011, p. 122).

Por lo que respecta al desarrollo gramatical es una de las habilidades lingüísticas donde los niños con SD presentan mayor deterioro ya que según afirman varios autores "Sus habilidades sintácticas son muy inferiores a las cognitivas y a la comprensión de vocabulario" (Abbeduto et al., 2007; Champan, 1995, 2003; Fowler, 1990; Roberts et al., 2007 citado en Galeote et al., 2010, p.138). La producción sintáctica suele estar más retrasada que la comprensión, si es comparada con niños con desarrollo típico, esto se manifiesta desde los primeros meses de edad puesto que la edad media para reproducir emisiones de dos palabras es de 36,9 meses, mientras que en los niños con desarrollo típico es hacia los 19 meses. Según Jekins (1993) existen dificultades específicas en la morfología verbal. Sus estudios han demostrado que los niños con SD manifestaban peor uso de los verbos auxiliares y pronombres (citado en Galeote et al., p. 139, 2010). En relación con la morfología flexiva, la cual hace referencia al género, número, modo... Lázaro, Garayzabal, y Moraleda (2013) argumentan que la memoria de los niños con SD almacena solo las formas más simples (singular, infinitivo) por una capacidad de almacenamiento limitada, aunque presentan un uso muy temprano y correcto de un gran número de palabras.

En cuanto a la adquisición del vocabulario Galeote et. al (2014) afirman que está bastante preservado. Por el contrario, de acuerdo con estos mismos autores, la comunicación gestual se suele considerar uno de los puntos fuertes de estos niños ya que utilizan gestos comunicativos más numerosos y complejos que los que utilizan los niños con desarrollo típico. Esto puede ser explicado debido a la dificultad para expresar mediante el lenguaje oral, por ello han de sustituirlo por gestos para establecer comunicación.

Por último, se considera que la dimensión pragmática, es decir, el uso del lenguaje, es el punto fuerte de los niños con SD. Kumin (1997) indica que los niños con SD se pueden desenvolver bien en este campo y llegar a formular mensajes apropiados para las personas que los escuchan. Sin embargo, presentan deficiencias en otros aspectos de la pragmática tales como hacer preguntas, pedir declaraciones o ceñirse a un tema. 
A partir de esta información, se considera relevante analizar los estudios recientes centrados en la intervención para el desarrollo de las dimensiones del lenguaje para establecer pautas futuras basadas en la evidencia científica.

\section{Método}

En estas líneas se presenta una revisión del estado del arte. Para la selección de los artículos se han tenido en cuenta los siguientes criterios de inclusión y de exclusión.

En cuanto a los criterios de inclusión fueron los siguientes:

- Artículos publicados en bases de datos como Google Scholar, Science Direct, Dialnet y Medline.

- Artículos científicos publicados en los últimos 10 años (2008-2018) puesto que es un criterio de búsqueda efectivo para encontrar artículos centrados en investigaciones recientes con métodos innovadores o las últimas tendencias.

- Artículos obtenidos a partir de las palabras clave y booleanos: lenguaje " $Y$ " comunicación "Y" síndrome de Down; habla "Y" síndrome de Down; vocabulario " $Y$ " síndrome de Down; morfología " $Y$ " síndrome de Down; Pragmática " $Y$ " síndrome de Down. También, en inglés: Language "AND" communication "AND" Down syndrome; speech "AND" Down Syndrome; vocabulary "AND" Down syndrome; morphology "AND" Down syndrome; pragmatic "AND" down Syndrome.

- La edad de intervención comprendida entre la infancia y la adolescencia. A pesar de fijar este criterio de edad, en algunos estudios comparativos, la muestra estaba compuesta por grupos de escolares y grupos en edad adulta. Se ha considerado que estos estudios con estas franjas de edad también eran relevantes porque el objetivo era valorar como, mediante cierto método, evolucionaba el vocabulario o el habla durante esos años.

- Artículos publicados en inglés, castellano y valenciano.

En cuanto a los criterios de exclusión fueron los siguientes:

- Estudios centrados en explicaciones teóricas de las dimensiones del lenguaje afectadas en los niños con SD.

- Artículos que no sean de intervención.

- Artículos relacionados con otras patologías.

- Artículos relacionados con procesos lectores y no con las dimensiones del lenguaje.

- Artículos repetidos en las bases de datos.

A partir de las palabras clave mencionadas anteriormente se realizó una búsqueda en las diferentes bases de datos obteniendo un total de 42 artículos de los cuales, atendiendo a los criterios de inclusión y exclusión, se seleccionaron 20 puesto, que los 22 restantes no hacían referencia al objeto de estudio, estaban repetidos en otras bases de datos o no contenían intervenciones. 


\section{Resultados}

En la Tabla 1 se describen los veinte artículos seleccionados para esta revisión bibliográfica en base a la siguiente información: autor y año del estudio, objetivos del estudio, descripción de la muestra, instrumentos de medida, tipo de estudio y diseño de la intervención, y resultados.

Tabla 1. Resultados

\begin{tabular}{|c|c|c|c|c|c|}
\hline \multicolumn{6}{|c|}{ Tabla 1. Resultados } \\
\hline Autores/año & Objetivos del estudio & Descripción de la muestra & Instrumentos de medida & $\begin{array}{l}\text { Tipo de estudio y diseño de la } \\
\text { intervención }\end{array}$ & Resultados \\
\hline Diez-Itza y Miranda (2007). & $\begin{array}{l}\text { Observar mediante diferentes } \\
\text { instrumentos de medida qué } \\
\text { categorías gramaticales están más } \\
\text { afectadas en los niños con SD. }\end{array}$ & $\begin{array}{l}12 \text { niños y adolescentes (5 chicos y } 7 \\
\text { chicas) con síndrome de Down } \\
\text { procedentes de la Asociación } \\
\text { síndrome de Down de Asturias. } \\
\text { Edades comprendidas entre } 7 \text { y } 19 \\
\text { años. }\end{array}$ & $\begin{array}{l}\text { Metodología RETAMHE. } \\
\text { Herramientas del Proyecto CHILDES. } \\
\text { Porgrama informático CLAN del } \\
\text { proyecto CHILDES. } \\
\text { Peabody Test (TVIP). }\end{array}$ & $\begin{array}{l}\text { Estudio de campo. } \\
\text { La recogida de datos se llevó a cabo } \\
\text { mediante la selección de muestras del } \\
\text { habla espontánea: las sesiones } \\
\text { consistieron en } 40 \text { min de } \\
\text { conversación espontánea, también se } \\
\text { le pedía al sujeto que narrase un } \\
\text { cuento, una visita al médico y una } \\
\text { excursión. }\end{array}$ & $\begin{array}{l}\text { Los resultados muestran que la } \\
\text { proporción de alteraciones no es } \\
\text { homogénea en todas las categorías } \\
\text { gramaticales, afectado más a los } \\
\text { artículos, preposiciones y } \\
\text { conjunciones. } \\
\text { La incidencia de errores morfológicos } \\
\text { va disminuyendo con la edad, de } \\
\text { modo que se debe mantener la } \\
\text { atención logopédica en la } \\
\text { adolescencia y edad adulta. }\end{array}$ \\
\hline $\begin{array}{l}\text { Cleland, Wood, Hardcastle, Wishart y } \\
\text { Timmins (2008). }\end{array}$ & $\begin{array}{l}\text { Examinar si la gravedad de los } \\
\text { trastornos del habla está relacionada } \\
\text { con el lenguaje y el nivel cognitivo y, } \\
\text { al mismo tiempo, clasificar los tipos } \\
\text { de errores que ocurren en el habla de } \\
\text { niños y adolescentes con síndrome } \\
\text { de Down. }\end{array}$ & $\begin{array}{l}15 \text { niños y jóvenes con SD, } 12 \text { chicos } \\
\text { y } 3 \text { chicas. } \\
\text { La edad estaba comprendida entre } \\
\text { los } 9 \text { y } 19 \text { años. }\end{array}$ & $\begin{array}{l}\text { Weschler Preschool and Primary } \\
\text { Scale of Intelligence (WPPSI-IIIUK). } \\
\text { The British Picture Vocabulary Scales } \\
\text { II (BPVS-II). } \\
\text { The Clinical Evaluation of Language } \\
\text { Fundamentals Preschool (CELF-P). } \\
\text { Diagnostic Evaluation of Articulation } \\
\text { and Phonology (DEAP). } \\
\text { Robbins and Klee clinical assessment } \\
\text { of oropharyngeal motor development } \\
\text { in young children (RK). }\end{array}$ & $\begin{array}{l}\text { Estudio de campo. } \\
\text { Todos los niños completaron una } \\
\text { batería de evaluaciones } \\
\text { estandarizadas de habla, lenguaje y } \\
\text { cognición. Las pruebas de habla y } \\
\text { lenguaje fueron llevadas a cabo por } \\
\text { un terapeuta calificado de habla y } \\
\text { lenguaje; las evaluaciones cognitivas } \\
\text { fueron llevadas a cabo por un } \\
\text { psicólogo infantil. La mayoría de los } \\
\text { niños completaron la batería en tres } \\
\text { sesiones de una hora. }\end{array}$ & $\begin{array}{l}\text { Las personas con síndrome de Down } \\
\text { presentan deficiencias en el lenguaje } \\
\text { expresivo y receptivo que no se } \\
\text { explican por su demora cognitiva. El } \\
\text { vocabulario receptivo es una fortaleza } \\
\text { en comparación con las habilidades } \\
\text { del lenguaje expresivo y receptivo, } \\
\text { pero no está claro si es más } \\
\text { avanzado que las habilidades } \\
\text { cognitivas no verbales. La mayoría de } \\
\text { los errores del habla fueron de } \\
\text { naturaleza evolutiva, pero todos los } \\
\text { niños con síndrome de Down } \\
\text { mostraron al menos un error de habla } \\
\text { atípico o no evolutivo. }\end{array}$ \\
\hline
\end{tabular}




\begin{tabular}{|c|c|c|c|c|c|}
\hline Calero, Robles y García (2010). & $\begin{array}{l}\text { Comprar mediante la escala EHPAP } \\
\text { (Evaluación de Habilidades y } \\
\text { Potencial de Aprendizaje para } \\
\text { Preescolar), las diferencias en } \\
\text { habilidades cognitivas, conductas } \\
\text { hacia el aprendizaje y potencial de } \\
\text { aprendizaje entre niños preescolares } \\
\text { con desarrollo típico y niños con SD. }\end{array}$ & $\begin{array}{l}64 \text { niños de edades entre } 3 \text { y } 6 \text { años. } \\
\text { La muestra está dividida en dos } \\
\text { grupos: El primero de } 32 \text { niños ( } 7 \\
\text { niñas y } 25 \text { niños) con SD de } 3 \text { a } 6 \\
\text { años de edad. } \\
\text { El segundo grupo de } 32 \text { niños ( } 11 \\
\text { niñas y } 21 \text { niños) con desarrollo típico } \\
\text { de } 3 \text { a } 6 \text { años de edad. }\end{array}$ & $\begin{array}{l}\text { Test breve de inteligencia Kaufman } \\
\text { (K-BIT). } \\
\text { EHPAP. Esta escala de habilidades } \\
\text { se complementa con la Escala de } \\
\text { Observación Conductual (EOS). }\end{array}$ & $\begin{array}{l}\text { Estudio comparativo. } \\
\text { El diseño seguido en este estudio se } \\
\text { ha llevado a cabo con } 2 \text { grupos } \\
\text { equivalentesen edad establecidos } \\
\text { según el diagnóstico: Sindrome de } \\
\text { Down y Desarrollo Típico. } \\
\text { Durante el proceso de evaluación se } \\
\text { han utilizado dos instrumentos el K-Bit } \\
\text { y la EHPAP. Todas las sesiones se } \\
\text { realizaron de forma individualizada } \\
\text { con una duración aproximada de dos } \\
\text { horas por niño con descansos entre } \\
\text { subtests. }\end{array}$ & $\begin{array}{l}\text { Existen diferencias significativas en la } \\
\text { ejecución de diferentes tareas entre } \\
\text { los grupos de SD comparados con los } \\
\text { de DT. Estos resultados muestran que } \\
\text { las principales diferencias de los } \\
\text { sujetos con SD respecto de los DT, se } \\
\text { encuentran en la modalidad auditivo- } \\
\text { verbal, tanto en memoria como en } \\
\text { procesamiento. } \\
\text { Ambos grupos mejoran su ejecución } \\
\text { en el post- test de la EHPAPA, en casi } \\
\text { todas las habilidades evaluadadas. Los } \\
\text { niños con SD mejorar en Memoria } \\
\text { visual, considerada un punto fuerte en } \\
\text { las personas con SD. } \\
\text { Además, muestran mejora en la } \\
\text { habilidad de toma de perspectiva, } \\
\text { puesto que se observa una mejor } \\
\text { respuesta de los niños con SD en la } \\
\text { interacción social. }\end{array}$ \\
\hline $\begin{array}{l}\text { Galeote, Rey, Checa y Sebastín } \\
\text { (2010). }\end{array}$ & $\begin{array}{l}\text { Mostrar datos normativos sobre el } \\
\text { desarrollo morfosintáctico en niños } \\
\text { con SD, en concreto, se pretendia } \\
\text { evalaur competencias commo la } \\
\text { morfologia y la complejidad } \\
\text { morfosintáctica. }\end{array}$ & $\begin{array}{l}153 \text { niños con SD de } 16 \text { a } 29 \text { meses } \\
\text { de edad mental divididos en } 7 \text { grupos. }\end{array}$ & $\begin{array}{l}\text { Inventario de Desarrollo Comunicativo } \\
\text { MacArthur-Bates (ICD-Down). }\end{array}$ & $\begin{array}{l}\text { Estudio de campo. } \\
\text { Se realizaron dos entrevistas a las } \\
\text { familias. En la primera entrevista se } \\
\text { explicaban los objetivos de la } \\
\text { investigación, las caracteristicas del } \\
\text { inventario y el contenido de las } \\
\text { difierentes secciones. En casa debian } \\
\text { observar a sus hijos durante una } \\
\text { semana y rellenar el inventario. } \\
\text { En la segunda entrevista se revisaba } \\
\text { el inventario. }\end{array}$ & 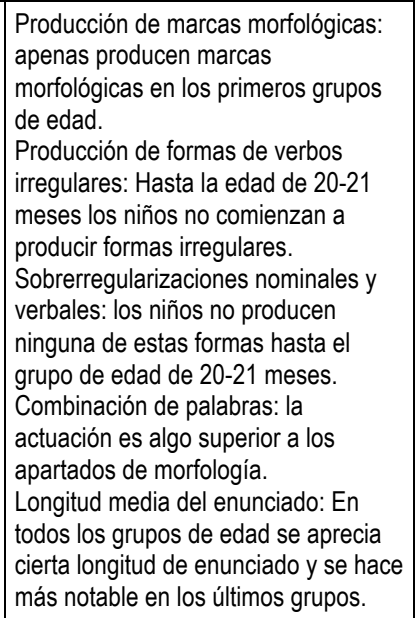 \\
\hline
\end{tabular}




\begin{tabular}{|c|c|c|c|c|c|}
\hline Moraleda (2011). & \begin{tabular}{|l|} 
Investigar si existian diferencias \\
significativas en el aprendizaje de la \\
morfosintaxis en función de la edad.
\end{tabular} & $\begin{array}{l}20 \text { personas con síndrome de Down, } \\
11 \text { chicos y nueve chicas } \\
\text { pertenecientes a la Asociación de } \\
\text { Sindrome de Down de Toledo. } \\
\text { Dos franjas de edad: de } 6 \text { a } 11 \text { años y } \\
\text { de } 12 \text { a } 14 \text { años. } \\
10 \text { participantes en cada franja. } \\
\text { Un grupo de entrenamiento y un } \\
\text { grupo de control por cada franja de } \\
\text { edad. }\end{array}$ & $\begin{array}{l}\text { Escala de inteligencia WISC-IV. } \\
\text { Batería de Lenguaje Objetiva y } \\
\text { Criterial (test BLOC-C). } \\
\text { Programa de entrenamiento } \\
\text { morfosintáctico. } \\
\\
\end{array}$ & \begin{tabular}{|l|} 
Estudio comparativo: Pre-test y Post- \\
test. \\
Se llevó a cabo la evaluación inicial a \\
nivel individual. Al mismo tiempo, se \\
realizaron tres sesiones de \\
preparación a las tres logopedas \\
encargadas de llevar el proceso. El \\
programa se realizó de forma \\
individual durante 30 sesiones de 30 \\
minutos de duración, se trabajaron \\
dos sesiones por semana. \\
Posteriormente, se volvieron a \\
evaluar los resultados. \\
\end{tabular} & $\begin{array}{l}\text { Resultados pre-test: no existen } \\
\text { diferencias significativas entre los } \\
\text { grupos de control y experimental en } \\
\text { ambas franjas de edad, tanto en el } \\
\text { área de morfologia como en la de } \\
\text { sintaxis. } \\
\text { Resultados postest del grupo } \\
\text { experimentall: diferencias significativas } \\
\text { entre el pre y el post tratamiento en el } \\
\text { área de morfologia y en el área de } \\
\text { sintaxis en ambas franjas de edad. } \\
\text { Resultados postest en los grupos de } \\
\text { control: no hay mejoras en el área de } \\
\text { la morfologia ni en el área de la } \\
\text { sintaxis en ninguna franja de edad. } \\
\end{array}$ \\
\hline $\begin{array}{l}\text { Pérez, Mendoza, Carballo, Fresneda } \\
\text { y Muñoz, (2012). }\end{array}$ & $\begin{array}{l}\text { Evaluar el rendimiento de la memoria } \\
\text { de trabajo de los niños con SD de } \\
\text { habla española, en una prueba de } \\
\text { pseudopalabras cuando los factores } \\
\text { de audición, vocabulario } \\
\text { ininteligibilidad estaban controlados. }\end{array}$ & \begin{tabular}{|l|} 
Dos grupos: \\
El grupo de síndrome de Down \\
formado por 23 niños con una edad \\
cronológica de 5.7 a 10.11 años y una \\
edad equivalente de vocabulario de \\
2.3 a 6.10 . Procedentes de la \\
Asociación de Sindrome de Down de \\
Granada. \\
Grupo de control formado por 13 \\
niños con desarrollo normal de \\
lenguaje, con una edar cronológica \\
de 3.4 a 5.9 años y cuya edad \\
equivalente de vocabulario era de 2.9 \\
a 6.10. Procedentes de centros \\
escolares de Granada.
\end{tabular} & $\begin{array}{l}\text { Pruebas de selección de la muestra: } \\
\text { Test de vocabulario en imágenes, } \\
\text { PEABODY. } \\
\text { Screening auditivo verbal par niños, } \\
\text { MAICO Pilot Hearing Test. } \\
\text { PLON-R } \\
\text { CEG } \\
\text { TCEG 2-4 } \\
\\
\end{array}$ & \begin{tabular}{|l|} 
Estudio Comparativo. \\
Cada grupo fue evaluado de manera \\
individual en su centro de referencia. \\
Se entregó a los padres un \\
cuestionario para identificar su nivel \\
educativo. Se aplicó una prueba de \\
pseudopalabras, la prueba se \\
administró de manera oral. El niño \\
tenia que repetir después de \\
escuchar el estimulo. Las sesiones se \\
grabaron con un audio de alta calidad. \\
Posteriormente, se realizaron las \\
transcripciones para el análisis \\
estadístico.
\end{tabular} & $\begin{array}{l}\text { Los niños con SD mostraron un } \\
\text { rendimiento deficiente en la repetición } \\
\text { de palabras y pseudopalabras, } \\
\text { existieron diferencias notables en } \\
\text { pseudopalabras simples y no se } \\
\text { observó un efecto de longitud de } \\
\text { palabras. }\end{array}$ \\
\hline
\end{tabular}




\begin{tabular}{|c|c|c|c|c|c|}
\hline $\begin{array}{l}\text { Galeote, Soto, Sebastín, Rey y } \\
\text { Checa (2012). }\end{array}$ & $\begin{array}{l}\text { Mostrar datos normativos sobre el } \\
\text { desarrollo del vocabulario, tanto en } \\
\text { compresión como en producción oral } \\
\text { y gestual, en niños con síndrome de } \\
\text { Down. }\end{array}$ & $\begin{array}{l}230 \text { niños con SD de } 8 \text { a } 29 \text { meses de } \\
\text { EM divididos en } 11 \text { grupos de EM. }\end{array}$ & \begin{tabular}{|l|} 
Inventario de Desarrollo Comunicativo \\
MacArthur-Bates (IDC-Down) para \\
niños con SD. \\
Escala de Desarrollo Psicomotor de la \\
Primera Infancia Brunet-Lézine- \\
Revisada.
\end{tabular} & \begin{tabular}{|l|} 
Estudio de campo. \\
Se llevaron a cabo dos entrevistas, \\
individuales o en pequeño grupo. En \\
la primera entrevista se explicaban los \\
objetivos de la investigación y las \\
características del inventario, también \\
se les pedía que observaran a sus \\
hijos en casa durante 1 semana antes \\
de rellenar el inventario. \\
En la segunda entrevista se \\
comprobaba que el inventario había \\
sido rellenado correctamente.
\end{tabular} & 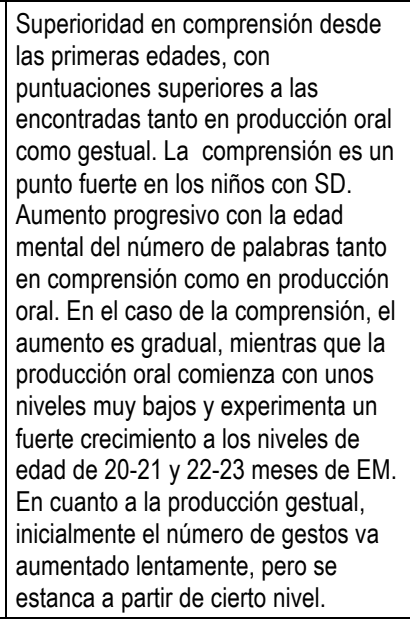 \\
\hline Polisenska y Kapalková (2013). & $\begin{array}{l}\text { Examinar la composición del lenguaje } \\
\text { receptivo y expresivo de los niños con } \\
\text { SD e investigar si existen vinculos } \\
\text { entre la gramáticalléxico y comparar } \\
\text { los grupos clínicos con el grupo de } \\
\text { desarrollo tipico. }\end{array}$ & $\begin{array}{l}87 \text { niños. } \\
13 \text { niños con sindrome de Down (SD) } \\
\text { procedentes de una guardaría para } \\
\text { niños con DI de Bratisisaava; } 6 \text { niños } \\
\text { con trastorno del lenguaje (TL) } \\
\text { pertenecientes a colegios públicos de } \\
\text { Bratislava; } 58 \text { niños con desarrollo } \\
\text { tipico (DT) procedentes de colegios } \\
\text { públicos de Bratislava. } \\
\text { Edades comprendidas entre los 3-4 } \\
\text { años. }\end{array}$ & $\begin{array}{l}\text { MacArthur-Bates Communicative } \\
\text { Development Inventories: Words and } \\
\text { Sentences TEKOS II. }\end{array}$ & \begin{tabular}{|l|} 
Estudio comparativo. \\
Los datos sobre el léxico y la \\
gramática evaluados en este estudio \\
fueron recogidos a traveses de una lista \\
de control parental basada en la \\
adaptación eslovaca MacAtrthr \\
Communicative Development \\
Inventory: Words and sentences \\
(CDI).
\end{tabular} & $\begin{array}{l}\text { Las composiciones del vocabulario } \\
\text { receptivo y expresivo del grupo de SD } \\
\text { y TL no diferia de la cantidad de } \\
\text { vocabulario de los niños con DT, esto } \\
\text { sugiere que el aprendizaje de } \\
\text { palabras del grupo clínico está } \\
\text { retrasado más que desviado. } \\
\text { Los niños con TL mostraron una } \\
\text { brecha más grande entre el } \\
\text { vocabulario expresivo y el } \\
\text { conocimiento receptivo de la palabra; } \\
\text { mientras que los niños con SD } \\
\text { mostraron un patrón comparable con } \\
\text { los niños con DT. } \\
\text { Los niños con TL mostraban pobres } \\
\text { herramientas gramaticales, por tanto } \\
\text { no habría asociación entre los } \\
\text { recursos léxicos y gramáticos de los } \\
\text { niños con TL. En cambio, las } \\
\text { herramientas gramaticales de los } \\
\text { niños con SD estaban equiparadas a } \\
\text { los recursos léxicos que tenían. }\end{array}$ \\
\hline
\end{tabular}




\begin{tabular}{|c|c|c|c|c|c|}
\hline $\begin{array}{l}\text { Visootsak, Hess, Bakeman, y } \\
\text { Adamson (2013). }\end{array}$ & $\begin{array}{l}\text { Comprobar si existían diferencias en } \\
\text { las habilidades lingüísticas y la } \\
\text { motricidad fina entre los niños con } \\
\text { síndrome de Down con cardiopatía } \\
\text { congénita, y los niños con síndrome } \\
\text { de Down sin cardiopatía congénita. }\end{array}$ & $\begin{array}{l}29 \text { sujetos (19 chicos y } 10 \text { chicas) } \\
\text { divididos en dos grupos: } 12 \text { niños con } \\
\text { SD y con cardiopatía congénita (SD + } \\
\text { CC), y } 17 \text { niños con SD sin } \\
\text { cardiopatía congénita (SD - CC). } \\
\text { La edad media de ambos grupos es } \\
\text { de } 3,2 \text { años. }\end{array}$ & $\begin{array}{l}\text { MacArthur Communication } \\
\text { Development Inventory (CDI). } \\
\text { Mullen Scales of } \\
\text { Early Learning. } \\
\text { Communication Play Protocol (CPP). }\end{array}$ & $\begin{array}{l}\text { Estudio comparativo. } \\
\text { Veintinueve niños con síndrome de } \\
\text { Down se observaron de forma } \\
\text { sistemática en las interacciones entre } \\
\text { padres e hijos utilizando el protocolo } \\
\text { de comunicación y reproducción para } \\
\text { evaluar su uso del lenguaje; también } \\
\text { completaron el Inventario de } \\
\text { Desarrollo de la Comunicación Mullen } \\
\text { Scales of Early Learning y MacArthur. } \\
\text { Los participantes fueron remitidos a la } \\
\text { Universidad Estatal de Georgia por } \\
\text { sus proveedores de atención médica. }\end{array}$ & $\begin{array}{l}\text { En comparación con los controles SD } \\
\text { - CC, el grupo SD + CC reveló } \\
\text { puntuaciones más bajas en múltiples } \\
\text { áreas, incluidas las habilidades } \\
\text { motrices finas y el vocabulario } \\
\text { expresivo y receptivo. Mientras que la } \\
\text { mayoría de las diferencias no fueron } \\
\text { estadisticamente significativas, el } \\
\text { recuento de palabras del Inventario de } \\
\text { Desarrollo de la Comunicación y } \\
\text { difiere significativamente entre los } \\
\text { grupos. } \\
\text { El hecho de que las enfermedades del } \\
\text { corazón pueden explicar parte de la } \\
\text { variación en el retraso del lenguaje } \\
\text { nos permite considerar los } \\
\text { mecanismos específicos que } \\
\text { subyacen al impacto de las } \\
\text { enfermedades del corazón en la } \\
\text { adquisición del lenguaje en niños con } \\
\text { síndrome de Down. }\end{array}$ \\
\hline Andreou y Katsarou (2013). & $\begin{array}{l}\text { Mostrar si las habilidades } \\
\text { morfosintácticas de los niños con SD } \\
\text { eran más pobres que las de los niños } \\
\text { con DT }\end{array}$ & $\begin{array}{l}10 \text { sujetos con SD: } 6 \text { niños y } 4 \text { niñas } \\
4,7 \text { y } 7,0 \text { años. } \\
10 \text { sujetos con DT: con edades } \\
\text { comprendidas entre } 4,2 \text { y } 6,8 \text { años. }\end{array}$ & $\begin{array}{l}\text { Prueba estandarizada de habilidades } \\
\text { morfosintácticas (Tzouriadou et al., } \\
\text { 2008). }\end{array}$ & $\begin{array}{l}\text { Estudio comparativo. } \\
\text { Cada participante fue evaluado } \\
\text { individualmente en su casa o en el } \\
\text { aula. Las tareas se entregaron } \\
\text { conjuntamente a todos y tenían } 45 \\
\text { minutos para rellenarlas. } \\
\end{array}$ & $\begin{array}{l}\text { La sintaxis receptiva y expresiva está } \\
\text { retrasada y severamente afectada en } \\
\text { los niños con SD. } \\
\text { Los niños con SD obtuvieron } \\
\text { puntuaciones mucho más bajas que } \\
\text { los niños con DT. }\end{array}$ \\
\hline $\begin{array}{l}\text { Galeote, Checa, Sánchez y Gamarro } \\
\text { (2013). }\end{array}$ & $\begin{array}{l}\text { Analizar la relación entre la atención } \\
\text { conjunta y el desarrollo del } \\
\text { vocabulario en una amplia muestra de } \\
\text { niños con SD. }\end{array}$ & $\begin{array}{l}131 \text { niños con SD procedentes de } \\
\text { Centros de Atención Temprana y de } \\
\text { Asociaciones de padres de niños con } \\
\text { SD y } 131 \text { niños con DT } \\
\text { pertenecientes a guarderías públicas } \\
\text { y privadas de Málaga. } \\
\text { Edades comprendidas entre los } 8 \text { y } \\
29 \text { meses de edad de desarrollo. }\end{array}$ & $\begin{array}{l}\text { Inventario de Desarrollo Comunicativo } \\
\text { MacArthur-Bates (CDI). } \\
\text { Escala de Desarrollo Psicomotor de la } \\
\text { primera infancia Brunet-Lézine- } \\
\text { Revisada. }\end{array}$ & $\begin{array}{l}\text { Estudio comparativo. } \\
\text { Se realizaron dos entrevistas, podían } \\
\text { ser individuales y en pequeños } \\
\text { grupos. En la primera entrevista se } \\
\text { explicaba los objetivos de la } \\
\text { investigación y las características del } \\
\text { inventario. Cuando los padres } \\
\text { entregaban el inventario, los } \\
\text { examinadores lo revisaban en otra } \\
\text { entrevista individual. La tarea de los } \\
\text { padres consistía en marcar los gestos } \\
\text { o conductas que sus hijos realizaban. }\end{array}$ & $\begin{array}{l}\text { Similitud entre los niños de ambos } \\
\text { grupos en todas las variables de } \\
\text { atención conjunta examinadas. La } \\
\text { diferencia más notable tenía que ver } \\
\text { con la superioridad de los niños con } \\
\text { SD en la comprensión. No se } \\
\text { encontró diferencias entre las } \\
\text { conductas protoimperativas y las } \\
\text { protodeclarativas. }\end{array}$ \\
\hline
\end{tabular}




\begin{tabular}{|c|c|c|c|c|c|}
\hline $\begin{array}{l}\text { Lázaro, Garayzabal, y Moraleda } \\
\text { (2014). }\end{array}$ & \begin{tabular}{|l} 
Evaluar si los niños con SD cometen \\
más errores en la formación de \\
plurales que los niños con DT.
\end{tabular} & $\begin{array}{l}90 \text { niños. } \\
\text { Grupo experimental: } 30 \text { niños con SD } \\
\text { contactados a través de la asociación } \\
\text { castellano manchega de SD con una } \\
\text { edad media de } 12,2 \text { años. } \\
\text { Grupos de control: } 30 \text { niños } \\
\text { equiparados por edad mental con una } \\
\text { edad media de } 6,5 \text { años contactados } \\
\text { a través de colegios públicos de } \\
\text { Castilla la Mancha y } 30 \text { iños } \\
\text { equiparados por nivel de vocabulario } \\
\text { con edad media de } 8,5 \text { años. }\end{array}$ & $\begin{array}{l}\text { Test Peabody. } \\
\text { Escala de Inteligencia WISC-IV. } \\
\text { Test Wug. }\end{array}$ & \begin{tabular}{|l|} 
Estudio comparativo. \\
Los padres de todos los niños fueron \\
informados sobre el estudio y \\
estuvieron de acuerdo con la \\
participación de sus hijos en el \\
mismo. Para llevar a cabo el estudio \\
se ha tutilizado el test Wug, este test \\
consiste en mostrar al niño un objeto \\
dibujado en una lámina, mientras que \\
el investigador lo señala y dice en voz \\
alta de qué se trata.
\end{tabular} & $\begin{array}{l}\text { Cuando se trataba de pasar de } \\
\text { singular a plural, los niños con SD } \\
\text { cometen más errores, no solo con } \\
\text { palabras sino tambiein con } \\
\text { pseudopalabras, que los niños del } \\
\text { grupo de control. } \\
\text { Las pseudopalabras que terminan en } \\
\text { vocal fueron respondidas mejor que } \\
\text { las que acaban en fonemas } \\
\text { consonánticos. } \\
\text { Todos los participantes presentan } \\
\text { dificultad cuando la regla del plural } \\
\text { obliga a poner la terminación -es con } \\
\text { respecto a cuando corresponde la } \\
\text { terminación -s. } \\
\text { La aplicación de reglas de orden } \\
\text { morfologgice está relacionada con las } \\
\text { caracteristicas fonológicas de los } \\
\text { estimulos. }\end{array}$ \\
\hline $\begin{array}{l}\text { Naess, Lervag, Lyster y Hulmes } \\
\text { (2015). }\end{array}$ & $\begin{array}{l}\text { Se trata de un estudio longitudinal } \\
\text { que tiene como objetivo examinar los } \\
\text { patrones del lenguaje de niños con } \\
\text { SD desarrollados a lo largo del tiempo } \\
\text { (vocabulario, gramática y memoria } \\
\text { verbal a corto plazo). }\end{array}$ & $\begin{array}{l}\text { La muestra está compuesta por dos } \\
\text { grupos: } 43 \text { niños con SD con edad } \\
\text { cronológica de } 6 \text { años; } 57 \text { niños con } \\
\text { DT unidos por edad mental. }\end{array}$ & $\begin{array}{l}\text { Weschler Preschool and Primary } \\
\text { Scale of Intelligence (WPPSI; } \\
\text { Wechlser, 2002). } \\
\text { British Picture Vocabulary Scale } \\
\text { (BPVS- II) y Picture Naming (WPPSI- } \\
\text { III). } \\
\text { Test of Reception of Grammar TROG- } \\
\text { R. } \\
\text { Memoria verbal a corto plazo: } \\
\text { WPPSI-R y Children's test of } \\
\text { Nonword Repetition. }\end{array}$ & \begin{tabular}{|l|} 
Estudio comparativo. \\
El grupo clínico y el grupo de control \\
fueron unidos por edad mental. Todos \\
los niños fueron evaluados tres veces \\
con una diferencia entre cada una de \\
las pruebas de 12 meses. Los niños \\
eran evaluados en las aulas de sus \\
colegios durante 3 sesiones \\
diferentes en dias consecutivos.
\end{tabular} & 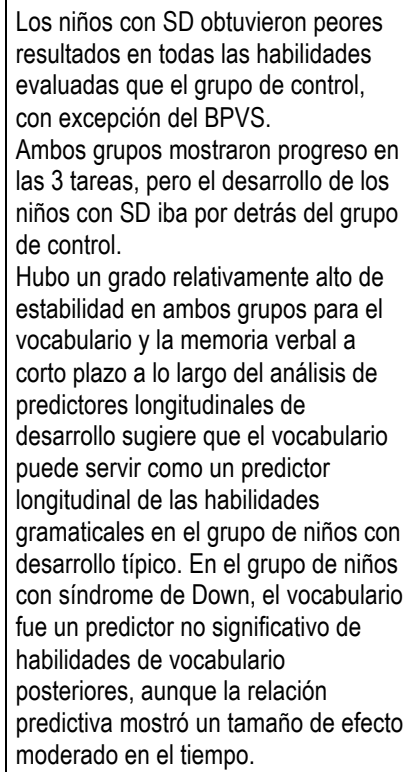 \\
\hline
\end{tabular}




\begin{tabular}{|c|c|c|c|c|c|}
\hline $\begin{array}{l}\text { Edgin, Tooley, Demara, Nyhuis, } \\
\text { Anand y Spanò (2015). }\end{array}$ & $\begin{array}{l}\text { El objetivo de este estudio era } \\
\text { mostrar el vinculo entre la alteración } \\
\text { del sueño, el desarrollo del lenguaje y } \\
\text { el comportamiento en niños con SD } \\
\text { comparados con un grupo de niños } \\
\text { con DT de la misma edad. }\end{array}$ & $\begin{array}{l}56 \text { participantes: } 32 \text { niños } \\
\text { diagnosticados con SD y } 24 \text { niños con } \\
\text { DT. } \\
\text { Dentro del grupo de niños con SD, se } \\
\text { encontraban los niños con } \\
\text { alteraciones en el sueño y niños sin } \\
\text { alteraciones. } \\
\text { La edad media es de } 3,5 \text { años. }\end{array}$ & $\begin{array}{l}\text { Actigraphy. } \\
\text { Children's Sleep Habits } \\
\text { Questionnaire. } \\
\text { MacArthur-Bates Communicative } \\
\text { Development Inventory. } \\
\text { Environment Analysis (LENA). } \\
\text { The Scales of Independent Behavior- } \\
\text { Revises (SIB-R). } \\
\text { Behavior Rating Inventory of } \\
\text { Executive Function-Preschool } \\
\text { (BRIEF-P). } \\
\text { M-CHAT. } \\
\text { Social Communication Questionnaire } \\
\text { (SCQ). }\end{array}$ & \begin{tabular}{|l} 
Estudio comparativo. \\
La Junta de Revisión Institucional \\
Biomédica de la Universidad de \\
Arizona aprobó todos los \\
procedimientos y se obtuvo el \\
consentimiento de los padres. \\
Los instrumentos para realizar el \\
estudio se enviaron por correo o se \\
entregaron en las casas de los \\
participantes, que se encontraban en \\
el estado de Arizona. Se les pidió a \\
los padres que completaran un \\
instrumento de detección de \\
problemas de sueño infantil, un \\
cuestionario de desarrollo, una \\
evaluación de lenguaje infantil, \\
cuestionarios de historia clinica y \\
medidas de informe de padres sobre \\
EF y sintomas de autismo.
\end{tabular} & $\begin{array}{l}\text { El } 60 \% \text { del grupo con SD manifiestan } \\
\text { alteraciones en el sueño, mientras } \\
\text { que en el grupo de los niños con DT, } \\
\text { el } 15 \% \text {. } \\
\text { Los resultados muestran que el grupo } \\
\text { con SD con deficiencias en el sueño } \\
\text { manifestaban dificultades con el } \\
\text { lenguaje expresivo (vocabulario y } \\
\text { sintaxis). Solo el } 31,6 \% \text { de niños con } \\
\text { SD del grupo de deficiencias del } \\
\text { sueño, supieron nombinar palabras, } \\
\text { en comparación con el } 80 \% \text { de los } \\
\text { que no presentaban deficiencias del } \\
\text { sueño. }\end{array}$ \\
\hline Knight, Kurtz y Georgiadou (2015). & $\begin{array}{l}\text { El objetivo de este estudio era } \\
\text { mostrar si la lectura en voz alta puede } \\
\text { mejorar la producción nel habla de los } \\
\text { niños con sindrome de Down. }\end{array}$ & $\begin{array}{l}8 \text { niños (2 chicos y seis chicas) con } \\
\text { sindrome de Down participaron en } \\
\text { este estudio. Sus edades oscilaron } \\
\text { entre } 11 \text { y } 14 \text { años. }\end{array}$ & $\begin{array}{l}\text { Lectura de palabras: a los } \\
\text { participantes se les mostraron las } \\
\text { tarjetas de vocabulario de las } \\
\text { palabras escritas. } \\
\text { Nombramiento: a los niños se les } \\
\text { mostraron las imágenes que } \\
\text { representan los ítems de los } \\
\text { estímulos. } \\
\text { Imitación: las pistas grabadas se } \\
\text { reprodujeron desde Windows Media } \\
\text { Player con la amplificación de dos } \\
\text { altavoces Labtec. }\end{array}$ & $\begin{array}{l}\text { Estudio de campo. } \\
\text { Se eligieron diez palabras individuales } \\
\text { que eran apropiadas para tareas de } \\
\text { lectura, asignación de nombres e } \\
\text { imitación. Las pruebas se } \\
\text { completaron en una sesión de } 20 \text { a } 40 \\
\text { minutos. Todos los participantes } \\
\text { fueron evaluados de forma individual } \\
\text { en su entorno familiar. El evaluador } \\
\text { solicitó una habitación tranquila. }\end{array}$ & 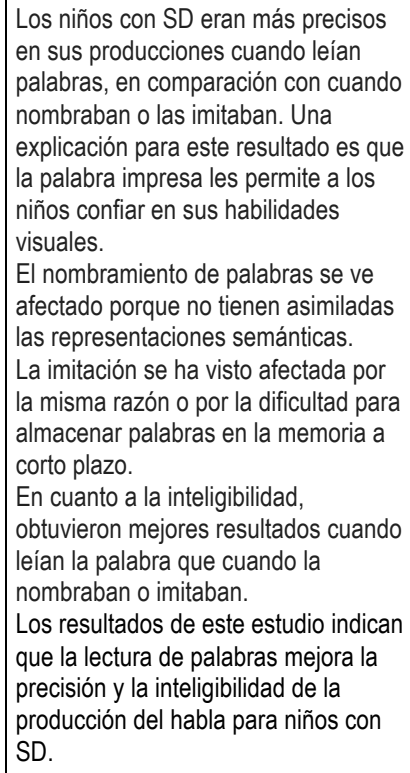 \\
\hline
\end{tabular}




\begin{tabular}{|c|c|c|c|c|c|}
\hline Eggers y Eerdenbrugh (2016). & $\begin{array}{l}\text { Analizar y describir las disfluencias } \\
\text { del habla en un grupo de niños con } \\
\text { SD de } 3 \text { a } 13 \text { años }\end{array}$ & $\begin{array}{l}26 \text { sujetos: } 12 \text { niños y } 14 \text { chicas con } \\
\text { SD con edades comprendidas entre } \\
3,03 \text { y } 12,06 \text { años. } \\
\text { Los niños fueron seleccionados de } \\
\text { diferentes escuelas y a través de } \\
\text { asociaciones de padres de niños con } \\
\text { SD de Flandes y Bélgica. }\end{array}$ & $\begin{array}{l}\text { PRAAT software. } \\
\text { Stuttering Severity Instrument. }\end{array}$ & $\begin{array}{l}\text { Estudio de campo. } \\
50 \text { muestras de habla espontánea } \\
\text { fueron grabadas durante sesiones de } \\
15 \text { minutos. Estas conversaciones } \\
\text { tuvieron lugar en aulas separadas de } \\
\text { las escuelas o instituciones a las que } \\
\text { pertenecía el niño. }\end{array}$ & $\begin{array}{l}\text { Los resultados mostraron que el } 30 \\
\text { por ciento de los niños con SD entre } \\
\text { los } 3 \text { y } 13 \text { años de edad de este } \\
\text { estudio tartamudeaba, que es mucho } \\
\text { más alto que la prevalencia en niños } \\
\text { con DT. Además, este estudio mostró } \\
\text { que el habla de los niños con SD tiene } \\
\text { una distribución diferente de los tipos } \\
\text { de disfluencias que el habla de los } \\
\text { niños en desarrollo típico. }\end{array}$ \\
\hline Witecy y Penke (2017). & $\begin{array}{l}\text { Mostrar si las habilidades del lenguaje } \\
\text { receptivo cambian desde la } \\
\text { infancia/adolescencia hasta la edad } \\
\text { adulta }\end{array}$ & $\begin{array}{l}58 \text { sujetos con SD divididos en dos } \\
\text { grupos: El primer grupo formado por } \\
\text { niños y adolescentes (13 chicas y } 18 \\
\text { chicos), con edades comprendidas } \\
\text { entre los } 4,6 \text { años a los } 19 \text { años. El } \\
\text { segundo grupo lo forman } 27 \text { adultos } \\
\text { (12 chicas y } 15 \text { chicos) con edades } \\
\text { comprendidas entre los } 20,8 \text { a los } 40, \\
3 \text { años. }\end{array}$ & $\begin{array}{l}\text { Cognición No verbal: evaluada por } \\
\text { Reasoning Scale of the Snijders- } \\
\text { Omen Nonverbal Intelligence Test } \\
\text { (SON-R 2.5- 7). } \\
\text { Comprensión gramática: evaluada por } \\
\text { el test TROG-D. } \\
\text { Memoria de trabajo fonológica: los } \\
\text { niños y adolesentes fueron evaluados } \\
\text { por el test SETK- } 3 \text {. Los adultos } \\
\text { fueron evaluados con el test K- ABC. }\end{array}$ & $\begin{array}{l}\text { Estudio comparativo. } \\
\text { Se utilizan tests estandarizados: } \\
\text { todos ellos fueron realizados por } \\
\text { cuatro examinadores en aulas de la } \\
\text { Universidad de Colonia } \\
\text { Tanto niños como adolescentes } \\
\text { fueron seleccionados a través de las } \\
\text { organizaciones de padres con hijos } \\
\text { con SD; los adultos fueron recluidos } \\
\text { de trabajos protegidos para adultos } \\
\text { con SD. }\end{array}$ & $\begin{array}{l}\text { Las habilidades de comprensión } \\
\text { sintáctica de sujetos con SD } \\
\text { continúan mejorando durante la } \\
\text { infancia y adolescencia y, que a partir } \\
\text { de entonces se alcanza y mantiene un } \\
\text { nivel. } \\
\text { La comprensión del lenguaje en } \\
\text { adultos se ve afectada por una } \\
\text { variedad de estructuras gramaticales } \\
\text { y el rendimiento receptivo parece } \\
\text { estar relacionado con las habilidades } \\
\text { cognitivas no verbales, la memoria de } \\
\text { trabajo fonológica y la complejidad } \\
\text { gramatical; las dificultades aumentan } \\
\text { con la longitud de la oración y la } \\
\text { complejidad gramatical. }\end{array}$ \\
\hline Smith, Naess y Jarrold (2017). & $\begin{array}{l}\text { Investigar qué áreas de la pragmática } \\
\text { tienen más afectadas los niños con } \\
\text { SD. }\end{array}$ & $\begin{array}{l}29 \text { sujetos con: } 16 \text { niñas y } 13 \text { niños } \\
\text { con SD, todos ellos con } 6 \text { años. }\end{array}$ & $\begin{array}{l}\text { CCC-2. } \\
\text { Picture Naming test (WIPPSI-III). } \\
\text { British Picture Vocabulary Scale } \\
\text { (BPVS-II). } \\
\text { PEDI. }\end{array}$ & $\begin{array}{l}\text { Estudio de campo } \\
\text { Para la recogida de datos se utilizaron } \\
\text { dos métodos: cuestionarios } \\
\text { electrónicos parentales y tests } \\
\text { clínicos. } \\
\text { En las sesiones clínicas los niños } \\
\text { eran evaluados individualmente en } \\
\text { una habitación del colegio. Todas las } \\
\text { respuestas expresivas eran } \\
\text { registradas manualmente y grabadas. }\end{array}$ & $\begin{array}{l}\text { Los niños con SD estaban } \\
\text { perjudicados en todas las áreas de la } \\
\text { pragmática en comparación con los } \\
\text { niños con DT. } \\
\text { El área de la comunicación no verbal } \\
\text { era significativamente más fuerte en } \\
\text { relación con las otras } 3 \text { subescalas } \\
\text { (vocabulario expresivo, vocabulario } \\
\text { receptivo, función social) } \\
\text { Mientras que el área de comprender } \\
\text { el contexto fue de la más débiles, lo } \\
\text { que afectaba a su habilidad para } \\
\text { expresarse y relacionarse en otros } \\
\text { contextos con gente nueva. }\end{array}$ \\
\hline
\end{tabular}




\begin{tabular}{|c|c|c|c|c|c|}
\hline $\begin{array}{l}\text { Mason, Stojanovik, Houston, y } \\
\text { Buckley (2017). }\end{array}$ & $\begin{array}{l}\text { Demostrar si mediante el uso de test } \\
\text { que evalúan la capacidad de } \\
\text { segmentación del habla en bebés, se } \\
\text { puede predecir el lenguaje de bebés y } \\
\text { personas con retrasos en el } \\
\text { desarrollo. }\end{array}$ & $\begin{array}{l}49 \text { sujetos divididos en dos grupos: } 14 \\
\text { niños con SD (4 niñas y } 10 \text { niños); } 35 \\
\text { niños con DT (18 niñas y } 17 \text { niños). } \\
\text { Edades comprendidas entre } 10 \\
\text { meses y } 32 \text { meses de edad. }\end{array}$ & $\begin{array}{l}\text { Early Social Communication Scales } \\
\text { (ESCS). } \\
\text { Mullen Scales of Early learning. } \\
\text { Preschool Language Scales- } 4 .\end{array}$ & $\begin{array}{l}\text { Se trata de un estudio longitudinal } \\
\text { comparativo. } \\
\text { Los sujetos son evaluados } 3 \text { veces } \\
\text { durante } 6 \text { meses. } \\
\text { Se recopilaron tests que evalúan el } \\
\text { lenguaje en bebés y personas con } \\
\text { retrasos en el desarrollo. Estos } \\
\text { incluyen: capacidad mental no verbal, } \\
\text { habilidades de segmentación del } \\
\text { habla y habilidades tempranas de } \\
\text { comunicación social. }\end{array}$ & $\begin{array}{l}\text { La capacidad de segmentación del } \\
\text { habla puede no determinar los } \\
\text { resultados del lenguaje en los bebés, } \\
\text { y la adquisición del lenguaje puede } \\
\text { estar más restringida por la } \\
\text { comunicación social y las habilidades } \\
\text { cognitivas generales. }\end{array}$ \\
\hline $\begin{array}{l}\text { Conners, Tungate, Abbeduto, Merrill y } \\
\text { Faught (2018). }\end{array}$ & $\begin{array}{l}\text { Determinar si las diferencias } \\
\text { individuales en el lenguaje y las } \\
\text { medidas de la memoria fonológica } \\
\text { son consistentes durante } 2 \text { años en } \\
\text { adolescentes con SD, y si estas } \\
\text { habilidades mejoran, se mantienen o } \\
\text { disminuyen. }\end{array}$ & $\begin{array}{l}42 \text { sujetos con SD con edades } \\
\text { comprendidas entre } 10 \text { y } 21 \text { años } \\
\text { procedentes de diferentes colegios y } \\
\text { de asociaciones de Síndrome de } \\
\text { Down de los EE.UU. }\end{array}$ & $\begin{array}{l}\text { Vocabulario receptivo: Peabody } \\
\text { Picture Vocabulary Test, } 4^{\mathrm{a}} \text { edición } \\
\text { (PPVT-4). } \\
\text { Memoria fonológica: Comprehensive } \\
\text { Test of Phonological Processing } \\
\text { (CTOPP) } \\
\text { Memory for Digits and Nonword } \\
\text { Repetition subtests. } \\
\text { Gramática: Test for Reception of } \\
\text { Grammar, 2ª edición. (TROG-2). }\end{array}$ & $\begin{array}{l}\text { Estudio de campo. } \\
\text { Cuarenta y dos adolescentes con } \\
\text { síndrome de Down (DS) de } 10 \text { a } 21 \\
\text { años completaron una batería que } \\
\text { medía la memoria fonológica y el } \\
\text { lenguaje dos veces, con } 2 \text { años de } \\
\text { diferencia. }\end{array}$ & $\begin{array}{l}\text { En SD la gramática receptiva y } \\
\text { expresiva permanecen estables } \\
\text { durante } 2 \text { años durante gran parte de } \\
\text { la adolescencia. Sin embargo, el } \\
\text { vocabulario receptivo mejora más de } \\
2 \text { años en la adolescencia, y el } \\
\text { vocabulario expresivo mejora a } \\
\text { principios de la adolescencia, pero se } \\
\text { mantiene estable en la adolescencia } \\
\text { tardía. La fuerza relativa en el } \\
\text { vocabulario receptivo más el } \\
\text { crecimiento continuo durante la } \\
\text { adolescencia sugiere que esta } \\
\text { habilidad podría capitalizarse en las } \\
\text { intervenciones de lectura y otras } \\
\text { materias académicas. }\end{array}$ \\
\hline
\end{tabular}




\section{Discusión}

Todos los artículos encontrados según los criterios establecidos en la metodología corresponden a los últimos 10 años. Es posible encontrar que el mayor número de publicaciones se produjo durante los últimos seis años, en concreto, en el año 2013 (Polisenská y Kapalkovà, 2013; Visootsak et al. 2013; Andreou y Katsarou, 2013.), en el año 2015 (Naess et al. 2015; Edgin et al, 2015; Knight et al, 2015.) y en el año 2017 (Witecy y Penke, 2017; Smith et al. 2017; Mason et al. 2017) siendo todas estas publicaciones estudios sobre el área morfosintáctica de los niños con SD.

Respecto al tipo de estudio, se ha podido observar que hay dos tendencias principales: los estudios comparativos con grupo de control y los estudios de campo. En este caso, los estudios comparativos prevalecen frente a los estudios de campo, puesto que estudios comparativos se han encontrado 12 (Calero et al. 2010; Moraleda, 2011; Pérez, Mendoza et al. 2012; Polisenska y Kapalkovà, 2013; Visootsakl et al. 2013; Andreou y Katsarou, 2013; Galeote et al. 2013; Lázaro et al. 2014; Naess et al. 2015; Edgin et al. 2015; Witecy y Penke, 2017; Mason et al. 2017; Conners et al. 2018); mientras que estudios de campo hay 8 (Diez- Itza y Miranda, 2007; Cleland et al. 2008; Galeote et al. 2010; Galeote et al. 2012; Knight, Kurtz y Georgiadou, 2015; Eggers y Eerdenbrugh, 2016; Smith, Naess y Jarrold, 2017; Conners, Tungate et al. 2018).

En cuanto a la edad de la muestra la preferencia está repartida entre dos vertientes: investigaciones cuya muestra pertenece a la edad escolar, en concreto se han hallado 11 (Diez- Itza y Miranda, 2007; Cleland et al. 2008; Moraleda, 2011; Pérez, Mendoza et al. 2012; Lázaro, Garayzabal y Moraleda, 2014; Naess et al. 2015; Knight, Kurtz y Georgiadou, 2015; Witecy y Penke, 2017; Smith et al. 2017; Conners, Tungate et al. 2018), e investigaciones dirigidas hacia la edad preescolar, de las cuales se han obtenido 9 (Calero et al. 2010; Polisenska y Kapalkovà, 2013; Edgin et al. 2015; Galeote et al. 2010; Galeote, Soto et al. 2012; Galeote, Checa et al. 2013; Mason et al. 2017).

Además, respecto a la distribución de la muestra solo 8 estudios de los 20 revisados cuentan con grupo de control (Moraleda, 2012; Pérez, Mendoza et al. 2012; Andreou y Katsarou, 2013; Galeote, Checa et al. 2013; Visootsak et al. 2013; Lázaro et al. 2014; Polisenská y Kapalková, 2014; Naess et al. 2015). En referencia a la duración de las intervenciones, solo 3 de los estudios revisados son investigaciones longitudinales (Naess et al. 2015; Mason et al. 2017; Conners et al. 2018), los 17 restantes son estudios transversales.

Asimismo, en cuanto a la metodología de las intervenciones, solo 5 de ellas abordan tanto el ámbito escolar como el familiar (Galeote, Soto et al. 2014; Galeote, Rey et al. 2010; Galeote, Checa et al. 2013; Smith, Naess y Jarrold, 2017; Polisenská y Kapalková, 2014), las 15 intervenciones restantes son desarrolladas exclusivamente en el ámbito escolar.

Por otro lado, con respecto a las dimensiones del lenguaje analizadas en las investigaciones revisadas, un primer bloque de trabajos está de acuerdo con que el área morfosintáctica de los niños con SD está gravemente afectada. En concreto, los resultados revelan que el colectivo de SD muestra dificultades en las categorías funcionales como las preposiciones o artículos, la formación de verbos irregulares, en la articulación de la palabra produciendo continuas dislalias y problemas con las marcas morfológicas. Aun así, los estudios revisados destacan que, si se tienen en cuenta los datos normativos y se diseña un programa de intervención adaptado a las 
características de cada individuo, el desarrollo del habla de los niños con SD puede evolucionar sin existir una franja de edad determinada. (Moraleda, 2011; Witecy y Penke, 2017; Galeote et al. 2010; Andreou y Katsarou, 2013; Diez y Miranda, 2007).

Asimismo, un segundo bloque de trabajos ha demostrado que los niños con SD también presentan dificultades a nivel morfológico, pues manifiestan problemas a la hora de formar la marca del plural y en la formación de verbos irregulares puesto que solo asimilan las formas más simples como el infinitivo y el singular (Lázaro et al., 2015; Lázaro, Garayzabal y Moraleda, 2013). Sin embargo, la aplicación de las reglas morfológicas en estos niños está alterada de forma específica en este síndrome y no pueden ser explicadas por niveles bajos de inteligencia.

Respecto a la adquisición y desarrollo del léxico los estudios revelan que está bastante preservado en los niños con SD, en comparación con otras habilidades lingüísticas como es la comunicación gestual y el vocabulario receptivo, los cuales se consideran puntos fuertes de estos niños. Sin embargo, los autores están de acuerdo en que la tendencia a realizar gestos disminuye conforme aumenta la producción oral (Galeote et al. 2014; Cleland, 2008; Polisenska y Kapalkovà, 2014). Por tanto, la mayor producción de gestos durante las edades más tempranas podría estar asociado a las dificultades que experimentan con el lenguaje oral. Como medida preventiva, se ha demostrado que la lectura en voz alta podía mejorar la precisión y la inteligibilidad del habla de los niños con síndrome de Down, ya que, según indican estos autores, la palabra impresa permite a los niños confiar en sus habilidades visuales (Knight et al., 2015).

La memoria verbal a corto plazo se encuentra bastante perjudicada porque los sujetos con SD no realizan el bucle fonológico para procesar la información lo que provoca que no haya representación fonológica y, por ende, que repetir contenidos o palabras les resulte difícil o que directamente olviden lo aprendido (Pérez et al., 2012). Todas estas dificultades, tanto en morfosintaxis, como en el desarrollo del vocabulario y la memoria verbal a corto plazo, pueden ocasionar disfluencias en el habla, como tartamudeo o desorden general de la producción verbal. Además, los estudios sugieren que estos impedimentos perjudican el correcto uso del lenguaje, es decir, la pragmática, lo que ocasiona dificultad para comprender el contexto, iniciar una conversación o desarrollar comunicación no verbal (Eggers y Eerdenbrugh, 2018; Smith et al., 2017).

En esta línea, otros estudios evidencian que la atención conjunta, la cual incluye el inicio de peticiones, las conductas protodeclarativas y las protoimperativas y el uso de la mirada para atender a los gestos de otras personas, es indispensable para el desarrollo de vocabulario y de las producciones gramaticales acordes con la edad cronológica de cada sujeto (Galeote et al., 2013).

Por otro lado, existen factores secundarios que pueden incrementar la gravedad del lenguaje de los niños con SD como es el hecho de sufrir una cardiopatía congénita o manifestar irrupciones en el sueño. Los trabajos revelan que ambos factores incrementan la dificultad en múltiples áreas como en el desarrollo de la motricidad fina y en el desarrollo del lenguaje expresivo y receptivo (Visootsak et al., 2013; Edgin et al., 2015).

Otros autores destacan la importancia de diseñar programas de intervención temprana que atiendan a sus déficits específicos para ayudar a mejorar el desarrollo de sus habilidades comunicativas y lingüísticas (Calero et al., 2010; Naess et al. 2015). Asimismo, se promueve el uso de evaluaciones tempranas en bebés que valoren 
habilidades como la comunicación no verbal y la atención conjunta con el objetivo de predecir el desarrollo del lenguaje y así planificar un correcto tratamiento logopédico (Mason et al. 2017).

Hay un consenso unánime, por parte de todos los autores de los artículos revisados, de que los niños con SD tienen dificultad en las diferentes dimensiones que componen el lenguaje, sobre todo, presentan especial dificultad en el área de la morfosintaxis. Tal y como apunta Moraleda (2011, p.121) "La morfosintaxis aparece como el punto más débil del lenguaje en personas con síndrome de Down y es sin duda uno de los aspectos que se han de atender de manera más constante y sistemática en la rehabilitación logopédica". Aun así, las investigaciones afirman que, con un buen programa de intervención desde edades tempranas, estas dificultades se pueden erradicar. Y, si, por el contrario, el programa de intervención se realiza durante la adolescencia tardía no importa porque los estudios revisados han demostrado que el área morfosintáctica puede evolucionar más allá de la adolescencia. Así pues, no hay que dejar apartados a los adolescentes con SD que no han recibido tratamiento logopédico anteriormente porque nunca es tarde ya que, en consonancia con Kumin "Aunque hay muy pocos adultos reciben terapia del habla y del lenguaje, las investigaciones han demostrado que los adultos pueden mejorar sus habilidades del habla y del lenguaje" (Kumin, 1996, citado en Moraleda, 2011, p. 126).

En cuanto a la morfología, es cierto que, a pesar de las pocas investigaciones sobre esta área, se sabe que presentan déficits, en consonancia con Lázaro et al. (2015, p.158) "Se demuestra un almacenamiento de memoria limitada, pero con un uso muy temprano y adecuado de un gran número de palabras". De acuerdo con estos mismos autores, estas reglas han de ser aprendidas por los niños a través de la interacción lingüística.

Respecto al vocabulario, las investigaciones sugieren que está bastante preservado, pero, de acuerdo con Kumin (1997, p. 93): "La experiencia y diferentes estudios muestran que los niños y los adultos con síndrome de Down pueden ampliar su vocabulario a lo largo de toda su vida. El vocabulario es el transmisor de tu mensaje; con un vocabulario extenso y una locución inteligible, puedes transmitir un mensaje aun cuando utilices frases cortas o finales morfológico incorrectos". Así pues, desde casa se puede potenciar el léxico con simples actividades como lectura de libros con imágenes sobre algún tema que le pueda llamar la atención o visualizar álbumes de fotos donde aparezcan objetos vistos recientemente y nombrarlos.

Por otro lado, la pragmática también es una de las áreas donde manifiestan dificultad ya que les cuesta comprender ciertos contextos, poder iniciar y seguir una conversación, mantener la mirada o interpretar la comunicación no verbal de otro individuo. En general, demuestran carencias en aspectos necesarios para poder comprender el entorno más próximo, pero, con ayuda de los terapeutas y de los padres se pueden hacer grandes progresos en este campo. También, se ha de destacar, que, a nivel de compresión verbal, los sujetos con SD presentan un nivel superior en comparación con la expresión verbal, por tanto, debería ser un aspecto positivo que se debería de tener en cuenta en el tratamiento logopédico que se realice para cualquiera de los sujetos ya que es un punto fuerte que debe ser potenciado.

Aunque la larga lista de problemas de comunicación que pueden desarrollar los niños con SD pueda resultar al principio desesperanzadora, se pueden realizar muchas actividades para ayudarlos tanto desde el ámbito familiar como desde el contexto escolar. Tal y como apunta Kumin (1997), los padres pueden incluir a los niños en una multitud de actividades y experiencias diarias que pueden ayudar a que supere 
dificultades en muchas áreas, por ejemplo, una actividad tan simple como ir a hacer la compra juntos y recordar el nombre de cada alimento puede ayudar a relacionar el concepto con su objeto y conseguir que perdure durante más tiempo en la memoria de trabajo.

Por su parte, los logopedas y maestros de AyL deben utilizar los instrumentos, técnicas y ejercicios que permitan al alumno mejorar y optimizar sus habilidades en la comunicación; su tarea ha de estar centrada en la mejora de la pronunciación y articulación haciéndola más comprensible, aumentar la longitud de sus frases, fomentar su vocabulario y propiciar la comunicación espontánea.

Tal y como apuntan Troncoso et al. (1999), esencialmente se aprende a hablar hablando, por lo que, en el trato diario, hablarles y escucharles son las mejores tácticas, intentando frenar la tendencia a corregirles insistentemente. Además, estos autores afirman que se ha comprobado que la lectura y escritura favorecen mucho el desarrollo de su lenguaje, por lo que se recomienda su inclusión desde edades tempranas.

En definitiva, el presente trabajo arroja luz sobre las dificultades que manifiestan los niños con SD en el ámbito del lenguaje y la comunicación que deben ser tenidas en cuenta a la hora de programar intervenciones educativas. Por un lado, revela la importancia de realizar programas de intervención temprana para modificar las ejecuciones deficitarias, sobre todo, si se atiende a sus déficits específicos, lo que podría ayudar a erradicar ciertas reglas lingüísticas incorporadas de manera incorrecta y desarrollar desde edades tempranas un uso adecuado del lenguaje. De la misma manera, muestra la eficacia de seguir realizando tratamientos logopédicos durante la etapa adolescente y adulta, pues las personas con SD puede seguir incorporando nuevos aprendizajes más allá de la edad escolar. Por otro lado, destaca la relevancia de tener en cuenta todas las dimensiones del lenguaje en los programas de entrenamiento (morfosintaxis, morfología, pragmática, léxico) y potenciar aquellas en las que los sujetos con SD se desenvuelvan mejor, como es el área de la pragmática, la cual, según Kumin (1997), es el punto fuerte de los niños con SD. Por último, este trabajo pretende reflejar la autenticidad que puede poseer cada persona con un cromosoma extra o sin él. Por tanto, se debe individualizar la enseñanza y no basarse prioritariamente en el número de cromosomas que posea. Así pues, todos estos resultados y observaciones pueden ser útiles a la hora de identificar aspectos de las habilidades comunicativas y lingüísticas que puedan servir de objetivos para futuras intervenciones con garantías de éxito.

De cara a futuras intervenciones sería recomendable indagar más sobre el resto de dimensiones del lenguaje en las que también los niños con SD manifiestan dificultades, como la morfología y la pragmática. Por otra parte, sería conveniente realizar estudios longitudinales con el fin de evaluar y observar el progreso del alumnado a lo largo del tiempo. Además, hacen falta más estudios centrados en alumnado escolarizado en la etapa de Infantil y Secundaria, puesto que la mayoría de los estudios están centrados en la Educación Primaria. Asimismo, apenas hay investigaciones que se lleven a cabo de manera combinada en el ámbito escolar y en el familiar, pues la mayoría de ellas se realizan solo en contexto escolar, y esta es una labor pendiente, puesto que familia y escuela son los dos contextos de socialización por excelencia. 


\section{Referencias}

Andreou, G., \& Katsarou, D. (2013). Language learning in children with down syndrome (DS): Receptive and expressive morphosyntactic abilities. Procedia - Social and Behavioral Sciences, 93, 921-924.

Calero García, M., \& Robles Bello, M., \& García Martín, M. (2010). Habilidades cognitivas, conducta y potencial de aprendizaje en preescolares con síndrome Down. Electronic Journal of Research in Educational Psychology, 8(1), 87-110.

Cleland, J., Wood, S., Hardcastle, W., Wishart, J., \& Timmins, C. (2010). Relationship between speech, oromotor, language and cognitive abilities in children with down's syndrome. International Journal of Language \& Communication Disorders, 45(1), 83-95.

Conners, F., Tungate, A., Abbeduto, L., Merrill, E., \& Faught, G. (2018). Growth and decline in language and phonological memory over two years among adolescents with down syndrome. Ajidd-American Journal on Intellectual and Developmental Disabilities, 123(2), 103-118.

Diez-Itza, E., \& Miranda, M. (2007). Perfiles gramaticales específicos en el síndrome de down. Revista De Logopedia Foniatría y Audiología, 27(4), 161-172.

Domènech, A. (2008). El papel de la interacción y la comunicación en las primeras adquisiciones lingüísticas de los niños con síndrome de Down. Revista médica internacional sobre el sindrome de Down, 12(3), 44-48.

Edgin, J. O., Tooley, U., Demara, B., Nyhuis, C., Anand, P., \& Spanò, G. (2015). Sleep Disturbance and Expressive Language Development in Preschool-Age Children with Down Syndrome. Child Development, 86(6), 1984-1998.

Eggers, K., \& Van Eerdenbrugh, S. (2018). Speech disfluencies in children with down syndrome. Journal of Communication Disorders, 71, 72-84.

Flores-Goñi, I. (2013). Síndrome de Down e integración en Educación Infantil (Trabajo de Fin de Grado). Universidad Internacional de La Rioja, facultad de educación.

Flórez, J. \& Ruiz, E. (2006). Cap. II Síndrome de Down. Síndromes y apoyos: Panorámica desde la ciencia y las asociaciones, 48-76.

Galeote, M., \& Checa, E., \& Sánchez, C., \& Gamarro, A. (2013). Relaciones entre atención conjunta y desarrollo del vocabulario en niños con síndrome de Down. Revista de Investigación en Logopedia, 3(2), 76-95.

Galeote, M., Rey, R., Checa, E., \& Sebastián, E. (2010). El desarrollo de la morfosintaxis en niños con síndrome de Down: primeros datos normativos. Revista Síndrome de Down, 27(4), 138-148.

Galeote, M., Soto, P., Sebastián, E., Rey, R., \& Checa, E. (2012). La adquisición del vocabulario en niños con síndrome de Down: datos normativos y tendencias de desarrollo. Infancia y Aprendizaje, 35(1), 111-122.

Gallardo, B. (2000). El Síndrome de Down: un reto para el pediatra de hoy. Acta Pediatría, 3, 22-2.
Knight, R., Kurtz, S., \& Georgiadou, I. (2015). Speech production in children with down's syndrome: The effects of reading, naming and imitation. Clinical Linguistics and Phonetics, 29(810), 598-612.

Kumin, L. (1997). Cómo favorecer las habilidades comunicativas de los niños con síndrome de Down. Barcelona: Paidós.

Lazaro, M., Garayzabal, E., \& Moraleda, E. (2014). Habilidades morfológicas de los niños con desarrollo típico y síndrome de Down. Revista de Logopedia, Foniatría y Audiología, 34(4), 157-162.

Mason-Apps, E., Stojanovik, V., Houston-Price, C., \& Buckley, S. (En prensa). Longitudinal predictors of early language in infants with down syndrome: A preliminary study. Research in developmental disabilities.

Næss, K. B., Lervåg, A., Lyster, S. H., \& Hulme, C. (2015). Longitudinal relationships between language and verbal shortterm memory skills in children with down syndrome. Journal of Experimental Child Psychology, 135, 43-55.

Pérez, D., Mendoza, E., Carballo, G., Dolores Fresneda, M., \& Muñoz, J. (2012). Repetición de pseudopalabras en niños con síndrome de down. Onomázein, 2(26), 377-390.

Pérez Chávez, D. A. (2014). Síndrome de Down. Revista De Actualización Clínica Investiga, 45, 2357-2361.

Polišenská, K., \& Kapalková, S. (2014). Language profiles in children with down syndrome and children with language impairment: Implications for early intervention. Research in Developmental Disabilities, 35(2), 373-382.

Moraleda, E. (2011). Análisis del desarrollo morfosintáctico en personas con síndrome de down en el periodo infantil y adolescente. Revista De Investigación En Logopedia, 1(2), 121-129.

Smith, E., Næss, K. B., \& Jarrold, C. (2017). Assessing pragmatic communication in children with down syndrome. Journal of Communication Disorders, 68, 10-23.

Troncoso, Del Cerro y Ruiz, (1999). El desarrollo de las personas con síndrome de Down: una visión longitudinal. Revista Siglo Cero, 30(4), 7-26.

Tzouriadou, M., Singolitou, E., Anagnostopoulou, E. \& Vakola, I. (2008). Psychometric criterion of Language Adequacy (L-a-To). Thessaloniki: Aristotle University of Thessaloniki, Ministry of Education.

Visootsak, J., Hess, B., Bakeman, R., \& Adamson, L. B. (2013). Effect of congenital heart defects on language development in toddlers with Down syndrome. Journal of Intellectual Disability Research, 57(9), 887-892.

Wechsler, D. (2002). Wechsler preschool and primary scale of intelligence (3rd ed.). San Antonio, TX: Psychological Corporation.

Witecy, B., \& Penke, M. (2017). Language comprehension in children, adolescents, and adults with down syndrome. Research in Developmental Disabilities, 62, 184-196. 